\title{
Multiphase flow above explosion sites in debris-filled volcanic vents: insights from analogue experiments
}

\author{
Pierre-Simon Ross $^{1}{ }^{*}$, James D.L. White ${ }^{1}$, Bernd Zimanowski ${ }^{2}$, Ralf Büttner ${ }^{2}$ \\ 1. Department of Geology, University of Otago, PO Box 56, Dunedin, New Zealand \\ 2. Physikalisch-Vulkanologisches Labor, Universität Würzburg, Pleicherwall 1, D-97070 Würzburg, Germany \\ * Corresponding author.
}

Now at: INRS-ETE, 490 rue de la Couronne, Québec (Qc), Canada, G1K 9A9

Email addresses: p_s_ross@ @otmail.com (P.-S. Ross); james.white@ stonebow.otago.ac.nz (J.D.L. White); zimano@mail.uni-wuerzburg.de (B. Zimanowski); buettner@geologie.uni-wuerzburg.de (R. Büttner)

\begin{abstract}
Discrete explosive bursts are known from many volcanic eruptions. In maar-diatreme eruptions, they have occurred in debris-filled volcanic vents when magma interacted with groundwater, implying that material mobilized by such explosions passed through the overlying and enclosing debris to reach the surface. Although other studies have addressed the form and characteristics of craters formed by discrete explosions in unconsolidated material, no details are available regarding the structure of the disturbed debris between the explosion site and the surface. Field studies of diatreme deposits reveal cross-cutting, steep-sided zones of non-bedded volcaniclastic material that have been inferred to result from sedimentation of material transported by "debris jets" driven by explosions. In order to determine the general processes and deposit geometry resulting from discrete, explosive injections of entrained particles through a particulate host, we ran a series of analogue experiments. Specific volumes of compressed (0.5-2.5 MPa) air were released in bursts that drove gas-particle dispersions through a granular host. The air expanded into and entrained coloured particles in a small crucible before moving upward into the host (white particles). Each burst drove into the host an expanding cavity containing air and coloured particles. Total duration of each run, recorded with high-speed video, was approximately $0.5-1$ second. The coloured beads sedimented into the transient cavity. This same behaviour was observed even in runs where there was no breaching of the surface, and no coloured beads ejected. A steep-sided body of coloured beads was left that is similar to the cross-cutting pipes observed in deposits filling real volcanic vents, in which cavity collapse can result not only from gas escape through a granular host as in the experiments, but also through condensation of water vapour. A key conclusion from these experiments is that the geometry of cross-cutting volcaniclastic deposits in volcanic vents is not directly informative of the geometry of the "intrusions" that formed them. An additional conclusion is that complex structures can form quickly from discrete events.
\end{abstract}

\section{Introduction}

During recent decades, significant progress has been made in the understanding and modelling of steady-state volcanic eruptions, those displaying a relatively stable behaviour over time (e.g., Wilson et al., 1980; Sparks, 1986; Woods, 1988; Koyaguchi, 2005). Discrete volcanic eruptions, in contrast, involve non-steady conditions and are comparatively poorly understood and difficult to model (e.g., Clarke et al., 2002; Dufek and Bergantz, 2005; Starostin et al., 2005). Discrete eruptions imply that volcanic vents are filled by more-orless stagnating debris between eruptive pulses (White, 1991), and this results in eruptive styles different from open-vent conditions.

Some insights into the type of structures formed in such conditions can be gained from geological field studies of eroded vents, such as diatremes (e.g., Lorenz, 1986; White, 1991) or diatreme complexes (White and McClintock, 2001). Cross-cutting tephra bodies within volcanic infill (Figs. 1a-1c) have been inferred to preserve the trace of the passage of "debris jets" (McClintock and White, 2006; Ross and White, 2006). By "debris jet" we mean an upward-flowing stream of particles and low-density fluids formed above subterranean explosion sites such as those in volcanic vents or above artificial blasts. In volcanic vents, debris jets are inferred to consist of vertically travelling volcaniclastic debris (newly fragmented magma and preexisting clasts), magmatic gases and, for phreatomagmatism, external water in vapour $+/$ - liquid form. It remains impossible from field studies alone to constrain the detailed behaviour of such flows, so we conducted laboratory experiments using analogue materials to learn more about them. Our experiments were highly successful in reproducing steep cross-cutting bodies (Figs. 1d-1e) and allowed us to determine the general processes and deposit geometry resulting from 
discrete, explosive injections of entrained particles through a particulate host.

\section{Methods}

Explosive volcanic eruptions involve large amounts of gas; for an explosion at depth within a debris-filled vent, gasses will expand and move upward toward the surface, entraining juvenile and pre-existing particles. Once these particles are entrained, and suspended in the gas phase, a gas-dominated multiphase flow will propagate upward into pre-existing debris. To reproduce these flows experimentally, we created the upward-moving gas-particle mixture by suddenly releasing a predetermined amount of compressed air $(0.5-2.5 \mathrm{MPa})$ at the base of a small crucible filled with 200-300 $\mu \mathrm{m}$ glass beads having a red colour (Fig. 2). A "cavity" or "bubble" consisting of expanding air plus these entrained red beads then moved upward into a 14 or $28 \mathrm{~cm}$-thick layer of white glass beads or natural sand; the layer of "host" was much wider than the crucible diameter. Thin markers were placed in the host to better visualize its deformation. We did not use any liquid water in most experimental series, and the host was neither fluidized nor aerated before each run.

We filmed the experiments through a vertical glass window with two cameras (25 and 500 frames per second, respectively). We also recorded five timedependent physical parameters including the vertical force applied to the setup by the accelerating mass of particles, and the driving pressure beyond the valve (Fig. 2). A detailed description of the materials used, the experimental setup, the physical data acquisition system, and the scaling between natural flows and our experiments is provided by Ross et al. (submitted).

It is worth emphasizing that our setup differs significantly from fluidization rigs, in which compressed air or water - without any suspended particles - is injected from the base of a container, at a constant or slowly changing velocity, for typical durations of several minutes. Our experiments produce discrete bursts lasting less than one second and involve fixed amounts of highly compressed air, released all at once by opening a magnetic valve. Both particles and gas, rather than only gas or water, are injected at the base of the container. Steady state fluidization experiments (e.g., Woolsey et al., 1975; Walters et al., 2006) do not reproduce discrete, explosive injections of entrained particles through a particulate host, which is the phenomenon we wished to study.

\section{Experimental results}

The runs discussed here only represent part of our experimental program (series A to $\mathrm{H}$ in Ross et al., submitted) and only involved glass beads, both as host and injected material. All beads were dry except for the host during series $\mathrm{H}$, which is discussed separately below. The runs involving dry glass beads only (series A to $\mathrm{G})$ were designed to learn more about gas-particle injections though other particles in general (processes, deposits), and to test the effects of changing (a) the initial gas pressure in the reservoir; (b) the injection depth (host thickness); and (c) the particle size of the host glass beads. We tested two injection depths $(14 \mathrm{~cm}$ and $28 \mathrm{~cm}$ ) and three sizes of host white beads (100-200, 200-300 and 300-400 $\mu \mathrm{m}$ ); the initial gas pressures were chosen to produce both "erupting" and "non-erupting" runs.

During erupting runs, some of the injected red beads were tossed into the air, whereas during nonerupting runs, all of the injected particles remained confined within the host. In both cases, the injections produced steep bodies of red beads in the centre of the host. These bodies are clear analogues to the crosscutting structures seen inside diatremes.

\subsection{Initial events (series A to G)}

The initial stages of the observed phenomena are the same for both erupting and non-erupting runs (Fig. 3, 4). After the solenoid valve starts to open at $\mathrm{t}=0 \mathrm{~ms}$, compressed air rushes to the base of the crucible and pushes the red beads from the crucible upward. This movement in turn moves the host upward, so that the horizontal markers, and eventually the surface of the host, start to deform. Shortly after, at $\mathrm{t} \approx 45-55 \mathrm{~ms}$, the maximum force is recorded (Fig. 5), indicating that acceleration of the injected beads is peaking. The maximum driving pressure is recorded slightly earlier, due to compressed air being released into the low pressure section beyond the valve and expanding to push the red glass beads upwards.

Injected beads become visible through the window less than $10 \mathrm{~ms}$ after the force peak, initially as a circle just above the base of the box-shaped container containing the host. The injection rapidly assumes a bubble shape (especially for shallow injections as in Fig. 3 ) and grows upwards and outwards as the compressed air expands. Space is made available for this 'bubble' by doming and uplift of the host. Doming is quite extreme for shallow injections, with maximum dome angles reaching over $45^{\circ}$ from horizontal, i.e. twice the angle of repose of the involved material, for erupting runs (not shown here). Doming is more subdued for deeper injections (e.g., Fig. 4), especially the non-erupting cases (not shown here). While the surface of the host and the top of the 'bubble' are moving up, the base of the 'bubble' pinches and inward granular flow of the host is observed at the base of the container. Pinching of the 'bubble' becomes evident at $\mathrm{t} \approx 100-160 \mathrm{~ms}$ depending on the experimental parameters.

The inward lateral flow of the host has some similarities with dam-break experiments summarized by Roche et al. (2004). In dam-break experiments, a fluid held in a lock is suddenly released into a much lower density fluid, such as air, to create a gravity current. The flow front assumes a wedge shape with a slope of about $60^{\circ}$ from horizontal. This resembles what is observed at the base of the model during our experiments, except that we are dealing with inwardly directed flow. In a natural volcanic vent there would not a flat bottom as in the experiments, so such a strong inward flow might not occur (although if the surficial material consisted of unconsolidated sediment sitting on bedrock, the situation might resemble the "flat-bottom" of the present experiments). On the other hand, volcanic vents generally narrow with depth, and an inward-slanting floor would enhance inward flow. Future simulations 
should inject the gas-particle dispersion several centimetres or more above the base of the host container to assess the strength of the "flat bottom" effect in producing strong inward flows.

Remaining events during the experimental runs depend on whether the injections will erupt or not, and on the injection depths (host thicknesses).

\subsection{Remaining events for non-erupting runs (series B, D, F, G)}

Shallow injections. For non-erupting runs using a thin host, e.g. $14 \mathrm{~cm}$ of host and $0.5 \mathrm{MPa}$ initial air pressure (series B, D, F), the 'bubble' remains fully confined inside the host (Fig. 3). At these shallow injection depths, the 'bubble' rises to near the host surface and air is able to escape through the $\sim 5 \mathrm{~cm}$-thick roof. This relatively thin roof, although densely packed (at least compared to erupting runs) is actually quite permeable because the glass beads are nearly monodisperse (very well sorted). Therefore the 'bubble' progressively deflates in situ after attaining an elongate shape. Expanding gas is no longer pushing the injected red beads upward, so they sediment into the transient cavity. For the $14 \mathrm{~cm} / 0.5 \mathrm{MPa}$ runs, sedimentation becomes visible at $\mathrm{t} \approx 180 \mathrm{~ms}$ and the 'bubble' disappears completely at about $340 \mathrm{~ms}$, having left behind a cylindrical body of red beads.

Deeper injections. For non-erupting runs with deeper injections (series G: $28 \mathrm{~cm} / 1.0-1.5 \mathrm{MPa}$; not shown here), the roof is much thicker, so air cannot escape quickly enough through inter-particle flow in the roof to relieve the pressure in the 'bubble'. Therefore a distinct "gas pocket" - almost devoid of injected beads because they have already sedimented - rises through the host and eventually pierces its surface. We call these runs "non-erupting" because no or very few injected beads are ejected. Again at the end of the experiments, a narrow cylindrical body of injected red beads is visible.

\subsection{Remaining events for erupting runs (series A, C,} E, G)

Shallow injections. For erupting runs with shallow injections (14 cm / 1.0 MPa; series A, C, E; not shown), the bubble also deflates through air flow in the roof, but there is twice as much gas involved so the gentle in situ deflation described for the $14 \mathrm{~cm} / 0.5 \mathrm{MPa}$ case is impossible. Air flow through the roof of the 'bubble' combines with the momentum imparted to the domed host by the inflating 'bubble' to thicken this layer. Because the space available for expansion within the experimental rig is limited, the expanded host eventually fills this space completely. At this stage, there is no significant density difference between the former 'bubble' of air + red beads and the former domed host. All the airborne beads eventually fall back down, leaving layers of white and red beads at the top of the deposit. Because some of the injected red beads sediment downward in the transient cavity during the "air escape through the roof" phase, the final product of the experiments includes a flaring-upward or conical body of red beads.

Deeper injections. In the case of deeper injections, we have not increased the initial gas pressure enough to produce fully "erupting" runs entirely comparable to what has just been described. A nearly erupting case is provided by our series $\mathrm{G}$, $28 \mathrm{~cm} / 2.0 \mathrm{MPa}$ runs. In the experiment illustrated in Figs. 4 and 5, the 'bubble' of injected red beads + air comes to within about $5 \mathrm{~cm}$ of breaching the surface of the gently domed host (frame 298). Compared to the shallower erupting runs, however, the decrease in visible density of the "dome" is minimal. Because the base of the bubble is pinching rapidly at this stage, red beads actually become involved in a dense intra-bubble fountain (frames 258, 298); this fountain is responsible for most of the cylindrical body of red beads left behind. At this stage, the red beads that had been held at the top of the 'bubble' fall into the bubble over the next $0.2 \mathrm{~s}$. This is rendered possible because air inside the 'bubble' flows through the overlying host in closely spaced mmwide conduits that propagate upward and outwards. The initial stage of this propagation is visible at the top of the bubble in frame 298 (arrows). The conduits rapidly enlarge to $\mathrm{cm}$-widths (frame 338) and soon the domed host above the 'bubble' contains more air than glass beads (by volume), developing an undulating top surface (frame 428). The remaining frames show the final stages of the collapse. No red beads ever make it to the ambient "atmosphere".

\subsection{Influence of different experimental parameters (series A to G)}

The most important flow-controlling parameters in our experiments are the injection depth (host thickness) and the initial gas pressure (the volume of gas, after expansion, is directly proportional to the initial pressure in the reservoir). In summary, doubling the injection depth would require slightly more than doubling of the initial gas pressure (or final gas volume) to obtain an "eruption" (the run shown on Fig. 4 is nearly "erupting"). In addition, the "decoupled air pocket" phenomenon is only visible for non-erupting runs with a thicker host (deeper injection). At shallow depths and low initial air pressures, the bubble-shaped injection of gas and red beads rises near enough to the top of the domed host to allow gas to escape gently through the roof.

By contrast to the dominant impact of the initial gas pressure and the injection depth, the effect of the host particle size on the flows is minimal for the size range investigated during series $A$ to $F$. These experiments all involved nearly monodisperse glass beads. Using a material that is not as perfectly shaped and well sorted, such as sand, induces noticeable changes in the behaviour of the system. For example, when using sand, a higher initial gas pressure is necessary to obtain results similar to the A $(14 \mathrm{~cm}$ glass beads host) or G (28 cm host) series. Further, 'bubbles' are more irregular in shape during their propagation into a sandy host. The volcaniclastic debris filling volcanic vents is commonly poorly sorted, so more experiments are needed with poorly sorted material to document the effect of host sorting on debris jets. 


\subsection{Impact of a moist host (series $H$ )}

Only exploratory runs have been carried out using a moist hoist, but the results warrant some comments. The addition of small amounts of water makes the glass beads cohesive, so the mode of host deformation observed is completely different. Dry non-fluidized monodisperse glass beads, used in all other series described here, are able to flow much like a liquid; despite extremely rapid doming of the host during our dry experiments, no fractures are ever created.

By contrast, a moist hoist fractures in a radial pattern during the doming phase because of its cohesion (Fig. 6). The fractured dome then disassembles into flying clumps of moist glass beads which eventually fall back down, leaving a steep crater. Some of the clumps adhere briefly to the rolled foam pad before falling back down. A steep crater is never observed after dry experiments, for which the final crater slope can be no more than the angle of repose of the granular material.

Obviously the presence of moisture in the host changes its behaviour significantly. Adding larger amounts of liquid water would result in a slurry, which we cannot investigate with the current setup. Slurries are inferred to exist inside the vents of Surtseyan eruptions (Kokelaar, 1983), and would flow even more readily than the dry glass beads.

\section{Applicability to diatremes}

Our experiments were primarily designed to simulate discrete debris jets within volcanic vents such as diatremes. Such jets are assumed to be complex multiphase flows, but very little is currently known about their behaviour, particle concentration, temperature, propagation mechanism, etc. because they are not directly observable. As a first approximation we assumed that an imperfectly scaled, simplified system consisting of coloured glass beads and compressed air, propagating upward into a dry granular host consisting of white glass beads, could reproduce key aspects of volcanic debris jets within diatremes.

In nature a discrete explosion, taking place within volcaniclastic material infilling a vent structure, would fragment some of the magma, and entrain resultant new juvenile particles, plus some pre-existing vent-filling debris, into an expanding subterranean debris jet or 'bubble', which would be highly buoyant relative to enclosing material because the moving mixture would contain a large proportion of low-density fluids. In the laboratory, injected air and coloured beads directly formed a bubble-shaped two-phase flow when propagating into the host. We did not model the volcanic explosion, the fragmentation of the magma and the entrainment of pre-existing debris into the jet, nor the behaviour of explosions taking place near enough to the rigid vent-structure walls to interact with them. Our analogue 'bubbles' propagated mainly by pushing the host upwards and outwards, eventually producing a relatively steep 'dome' for shallow injections. Similar surface doming effects were observed above the sites of artificial underground explosions (Ross et al., submitted). For deeper experimental injections, this doming effect was much more subdued, which is probably more realistic in terms of how debris jets behave within diatremes.

In nature, the 'bubble' of fluids and injected particles would expand and rise only to a certain point, dependant on the confining pressure of the overburden and the quantity of gas involved. Therefore the multiphase flow may or may not reach the ground surface. If it does not, the 'bubble' could collapse underground by various processes described above. During collapse of the 'bubble', the host would flow inwards to occupy newly available space, whereas the debris formerly suspended in the low-density fluids would sediment downwards. The final deposit would be a subvertical, non-bedded, cylindrical or conical body of volcaniclastic material.

There is no need for an "eruption" to take place to create such cross-cutting structures: the analogue flows produced steep bodies even when the injected material did not propagate to the surface. The experimental cross-cutting bodies were more irregular in shape for deep injections (Fig. 1d), and when using less well sorted materials such as sand (not discussed herein). This elegantly explains the irregularly shaped "blind" cross-cutting zones in real diatremes (Fig. 1a, 1c). If repeated several times such injections - whether erupting or wholly subterranean -, accompanied by collapsecapture of a central zone of initially upward-driven material, provide a compelling explanation for the origin and characteristics of multiple cross-cutting bodies that have been documented for diatreme deposits (e.g., Hearn 1968; White, 1991; Naidoo et al., 2004; Nowicki et al., 2004; Stiefenhofer and Farrow, 2004; Webb et al., 2004; McClintock and White, 2006; Ross and White, 2006).

A key conclusion from our experiments is that the geometry of cross-cutting granular deposits is not directly informative of the geometry of the "intrusions" that formed them. We initially envisaged that cylindrical pipes would be created by cylindrical injections (Ross and White, 2006), but in the laboratory cylindrical pipes are created by bubble-shaped injections.

\section{Applicability to Surtseyan activity}

What can these analogue flows tell us about subaerial tephra jets during Surtseyan eruptions? We identified nothing in the experimental runs strongly analogous to observed Surtseyan jets, which is perhaps unsurprising given that no slurries were involved. In experimental runs during which the injected material breached the surface, both host and driven beads were tossed into the air, but did not form momentum-driven streams of particles such as those seen at Surtsey in 1963 and during recent Icelandic eruptions (Thorarinsson et al., 1964). This may be in part a scaling effect, but we believe that in essence it indicates quite distinct processes at work. Surtseyan jets are often associated with more-sustained bursts, with opportunities for magma flow focusing that do not exist with discrete explosions of the sort investigated here. Whether such sustained and focused bursts can occur within vent structures filled with a predominantly clastic (as opposed to aqueous) host is not known. We concur with Kokelaar (1986) in inferring that Surtseyan and maar-diatreme eruptions are quite distinct. 


\section{Summary and conclusions}

In diatremes and other volcanic vents, steep cylindrical or cone-shaped bodies of material having differing properties from those of the surrounding vent-filling volcaniclastic material are often found. It has been proposed that such bodies result from the passage of "debris jets" generated after discrete subterranean bursts. To learn more about volcanic debris jets, we modelled experimentally the injection of gas-particle dispersions through a clastic host. Analogue materials and a finite amount of compressed air were used in the laboratory. Gas was made available by rapidly opening a valve therefore the injection of compressed air and coloured particles into the granular host was a brief $(<1 \mathrm{~s})$, discrete event, comparable to what occurs in nature following subterranean explosions.

The experimental injections assumed a bubble shape while expanding and propagating upward. We suggest this would also be the case in a real volcanic vent through cohesionless or low-cohesion material. In reaction, the upper part of the analogue host moved upward and outward above the injections, forming a transient 'dome'. The doming effect was much more pronounced for shallow injection depths. What happened next depended on the depth of injection and the nature of the host material. With shallow injection into a permeable host (glass beads), the compressed air in the "bubble' was able to diffuse rapidly through the roof. Meanwhile the coloured beads sedimented into the transient cavity, which was also closing laterally because of inward-directed granular flow of the host. Depending on the initial gas pressure in the reservoir, the two-phase flow was able to "erupt" or not; non-erupting injections produced cylindrical bodies of coloured beads whereas erupting runs produced flaring upward or conical deposits. Such steep "cross-cutting" bodies are characteristic of diatreme fills. However the discrete explosion-driven "debris jets" that we modelled appear fundamentally different from Surtseyan tephra jets.

\section{Acknowledgements}

PSR's travel to Germany was made possible by a bridging grant from the University of Otago (New Zealand). The manuscript was written during PSR's postdoctoral fellowship at the Geological Survey of Canada (funding: NSERC Visiting Fellowship in Canadian Government Laboratories, with support from the Chief Scientist Office, Earth Sciences Sector, Natural Resources Canada). JDLW acknowledges a subcontract from the Institute of Geological and Nuclear Sciences (New Zealand). We thank V. Lorenz, B.F. Houghton, M.T. Gudmundsson and M. McClintock for discussions about diatremes and phreatomagmatism.

\section{References}

Clarke, A.B., Voight, B., Neri, A. and Macedonio, G., 2002. Transient dynamics of vulcanian explosions and column collapse. Nature [London], 415: 897-901.

Dufek, J. and Bergantz, G.W., 2005. Transient two-dimensional dynamics in the upper conduit of a rhyolitic eruption: A comparison of closure models for the granular stress. Journal of Volcanology and Geothermal Research, 143: 113-132.
Hearn, B.C., 1968. Diatremes with kimberlitic affinities in north-central Montana. Science, 159: 622-625.

Kokelaar, B.P., 1983. The mechanism of Surtseyan volcanism. Journal of the Geological Society [London], 140: 939944.

Kokelaar, P., 1986. Magma-water interactions in subaqueous and emergent basaltic volcanism. Bulletin of Volcanology, 48: 275-289.

Koyaguchi, T., 2005. An analytical study for 1-dimensional steady flow in volcanic conduits. Journal of Volcanology and Geothermal Research, 143: 29-52.

Lorenz, V., 1986. On the growth of maars and diatremes and its relevance to the formation of tuff rings. Bulletin of Volcanology, 48: 265-274.

McClintock, M.K. and White, J.D.L., 2006. Large-volume phreatomagmatic vent complex at Coombs Hills, Antarctica records wet, explosive initiation of flood basalt volcanism in the Ferrar LIP. Bulletin of Volcanology, 68: 215-239.

Naidoo, P., Stiefenhofer, J., Field, M. and Dobbe, R., 2004. Recent advances in the geology of Koffiefontein Mine, Free State Province, South Africa. Lithos, 76: 161-182.

Nowicki, T., Crawford, B., Dyck, D., Carlson, J., McElroy, R., Oshust, P. and Helmstaedt, H., 2004. The geology of kimberlite pipes of the Ekati property, Northwest Territories, Canada. Lithos, 76: 1-27.

Roche, O., Gilbertson, M.A., Phillips, J.C. and Sparks, R.S.J., 2004. Experimental study of gas-fluidized granular flows with implications for pyroclastic flow emplacement. Journal of Geophysical Research, 109: paper B10201.

Ross, P.-S. and White, J.D.L., 2006. Debris jets in continental phreatomagmatic volcanoes: a field study of their subterranean deposits in the Coombs Hills vent complex, Antarctica. Journal of Volcanology and Geothermal Research, 149: 62-84.

Ross, P.-S., White, J.D.L., Zimanowski, B. and Büttner, R., submitted. Rapid injection of particles and gas into nonfluidized granular material: volcanological implications. Bulletin of Volcanology.

Sparks, R.S.J., 1986. The dimensions and dynamics of volcanic eruption columns. Bulletin of Volcanology, 48: 3-15.

Starostin, A.B., Barmin, A.A. and Melnik, O.E., 2005. A transient model for explosive and phreatomagmatic eruptions. Journal of Volcanology and Geothermal Research, 143: 133-151.

Stiefenhofer, J. and Farrow, D.J., 2004. Geology of the Mwadui kimberlite, Shinyanga district, Tanzania. Lithos, 76: 139160.

Thorarinsson, S., Einarsson, T., Sigvaldason, G. and Elisson, G., 1964. The submarine eruption off the Westmann Islands 1963-64. Bulletin Volcanologique, 27: 435-445.

Walters , A.L., Phillips, J.C., Brown, R.J., Field, M., Gernon, T., Stripp, G. and Sparks, R.S.J., 2006. The role of fluidisation in the formation of volcaniclastic kimberlite: grain size observations and experimental investigation. Journal of Volcanology and Geothermal Research, 155: 119-137.

Webb, K.J., Scott Smith, B.H., Paul, J.L. and Hetman, C.M., 2004. Geology of the Victor Kimberlite, Attawapiskat, Northern Ontario, Canada: cross-cutting and nested craters. Lithos, 76: 29-50.

White, J.D.L., 1991. Maar-diatreme phreatomagmatism at Hopi Buttes, Navajo Nation (Arizona), USA. Bulletin of Volcanology, 53: 239-258.

White, J.D.L. and McClintock, M.K., 2001. Immense vent complex marks flood-basalt eruption in a wet, failed rift: Coombs Hills, Antarctica. Geology [Boulder], 29: 935938.

Wilson, L., Sparks, R.S.J. and Walker, G.P.L., 1980. Explosive volcanic eruptions- IV. The control of magma properties 
and conduit geometry on eruption column behaviour. Geophysical Journal of the Royal Astronomical Society, 63: $117-148$

Woods, A.W., 1988. The fluid dynamics and thermodynamics of eruption columns. Bulletin of Volcanology, 50: 169193.

\section{Figures}

1. (a) Vertical cross-section through an idealized diatreme, based on observations from Coombs Hills (Antarctica) and elsewhere (modified from White and McClintock, 2001). (b) Field view from Coombs Hills showing a horizontal crosssection through cylindrical pipes a few metres in diameter. These pipes are richer in country-rock clasts than the surrounding non-bedded vent fill. (c) Field view from Hopi Buttes (Arizona) showing a subvertical section through a diatreme remnant. The irregular cross-cutting body indicated by the dashed outline is filled by coarser material. (d)-(e) Somewhat similar cross-cutting bodies (irregular and approximately cylindrical, respectively) formed during our experiments. Scale bar graduated in centimetres.

2. Simplified view of the experimental setup. For each run, the crucible is first filled with the material to be injected (most commonly red glass beads). The rectangular space between the wooden planks (on three sides) and the glass window is filled with the 'host' material (most commonly white glass beads), up to the marked dashed line for the 14 $\mathrm{cm}$ configuration. A finite amount of compressed air is stored in the rubber tube behind the magnetic valve. When the valve opens, compressed air rushes into the steel pipe and pushes the material from the crucible into the 'host' above.

3. The analogue experiments presented herein were designed to reproduce some aspects of the creation of steep crosscutting bodies in diatremes and other debris-filled volcanic vents. We envision the creation of these bodies by debris jets, which may erupt or not. This sequence of grabbed video frames shows run B2, a non-erupting run. This means that the red glass beads and compressed air injected from below into non-fluidized white glass beads of the same grain size fail to breach the surface. The time in $\mathrm{ms}$ is displayed the upper left corner of each image $(0 \mathrm{~ms}=$ trigger signal sent to valve) and the scale bars are graduated in $\mathrm{cm}$. Early on, only the lower blue marker is moving because the injection of red beads + gas is pushing the host upwards; peak driving pressure is recorded at $30 \mathrm{~ms}$. The surface of the host starts to move upward at $50 \mathrm{~ms}$, peak force is recorded at $56 \mathrm{~ms}$ and the injection of air and red beads becomes visible through the glass window $2 \mathrm{~ms}$ later. This injection will grow as an apparent circle until $\sim 88 \mathrm{~ms}$ and then as an ellipse until $120 \mathrm{~ms}$. During the growth of this 'bubble', the particle density decreases as more gas arrives. At about $120 \mathrm{~ms}$, the base of the 'bubble' starts to pinch noticeably because of inward movement of granular host (white beads). Sedimentation of red beads inside the 'bubble' becomes visible around $178 \mathrm{~ms}$, at which time the base of the bubble is fully closed. Sedimentation of red beads then forms a vertical cylindrical body, the construction of which takes until $338 \mathrm{~ms}$. During this time the bubble stops elongating upwards (maximum height is reached at $204 \mathrm{~ms}$ ) and rather deflates, allowing the domed host to move back downward. The final "crater" aspect of the surface of the host is due to subsidence of particles into the crucible underlying the rectangular container in which the host.

4. Grabbed frames for a nearly erupting run with a deeper injection (run G9). The time in ms is displayed in the upper left corner of each image $(0 \mathrm{~ms}=$ trigger signal sent to valve). The scale bars are graduated in $\mathrm{cm}$. See text for a description of the experiment.

5. Driving pressure and force record for runs B2 (illustrated in Fig. 3) and G9 (illustrated in Fig. 4). The rapidly rising driving pressure is due to compressed air being released into the low pressure section beyond the valve and expanding to push the red glass beads upwards in the crucible. The force becomes positive slightly later than the driving pressure does, becomes the glass beads need to start moving for unloading of the force transducer to occur. The force maxima, corresponding to the maximum upward acceleration of the glass beads, occur during the rapid pressure decline. Beyond the force peak, the slope of the curve corresponds to the relaxation characteristics of the measurement system. The arrows represent the overburden pressures of $0.002 \mathrm{MPa}$ and $0.004 \mathrm{MPa}$ corresponding to $14 \mathrm{~cm}$ and $28 \mathrm{~cm}$ of glass beads, respectively.

6. Grabbed frames for run $\mathrm{H} 2$ (14 cm of moist glass beads, 1.0 MPa initial gas pressure). See text for explanation. 

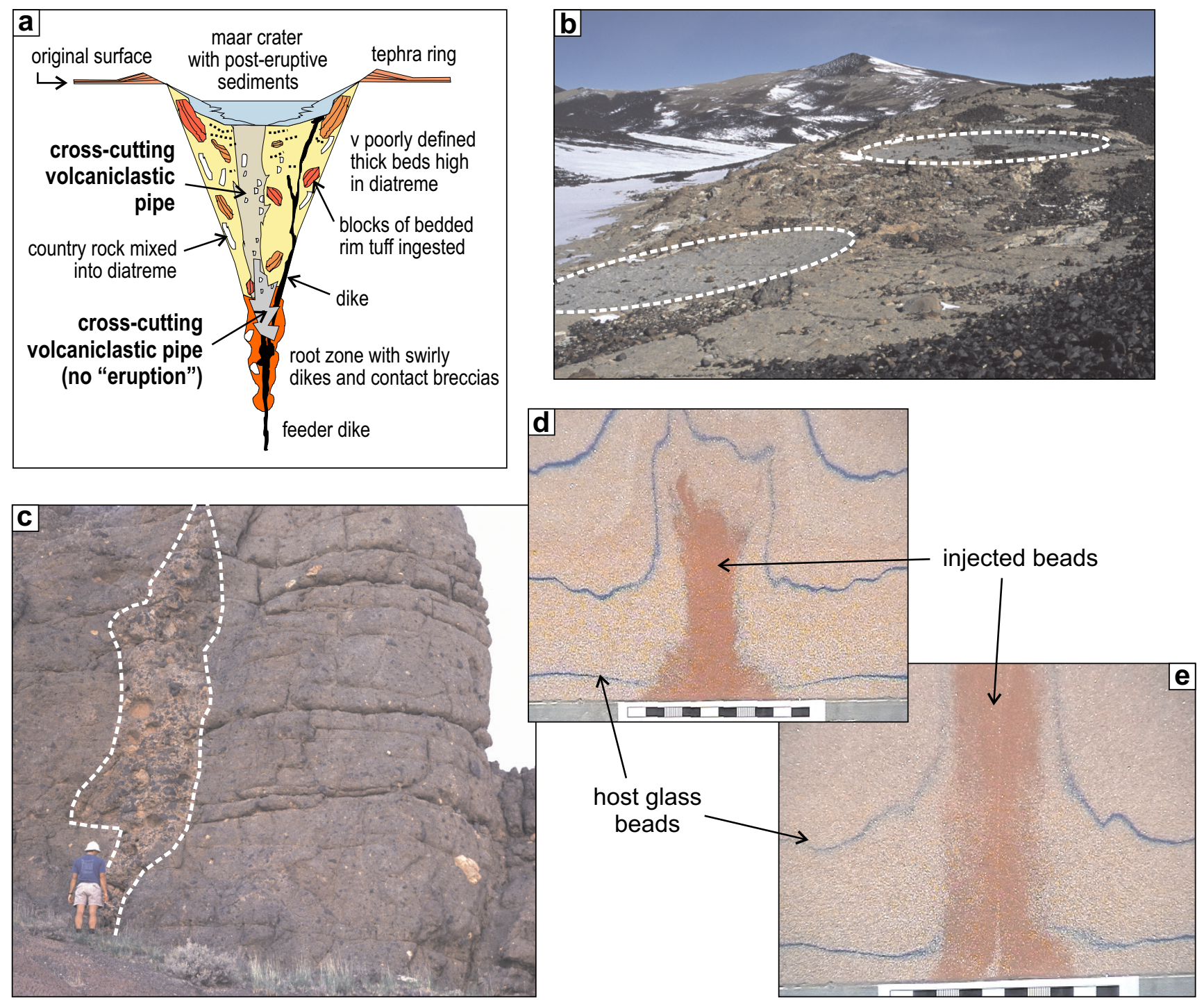

ROSS et al. (JVGR) Fig. 1 


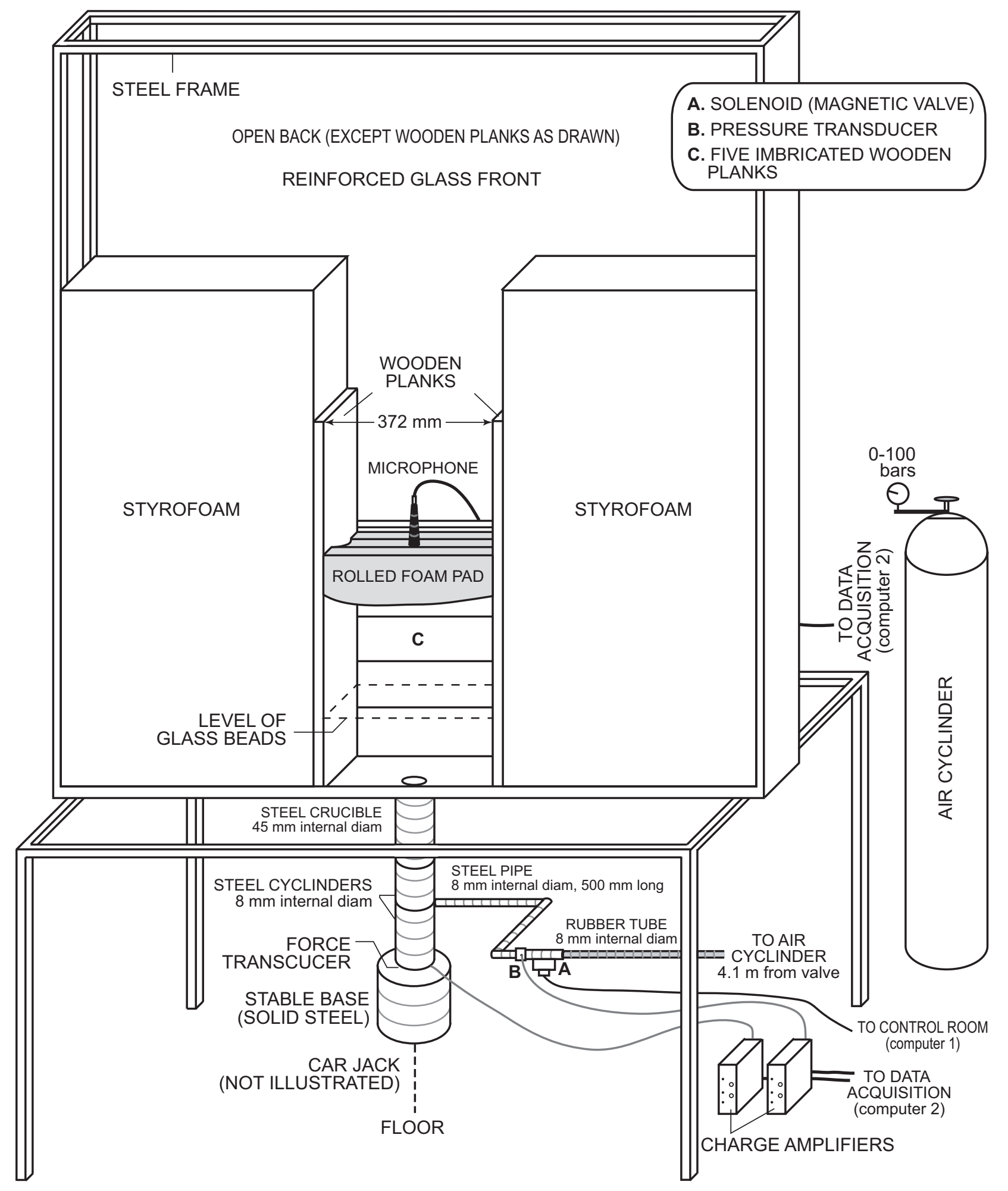



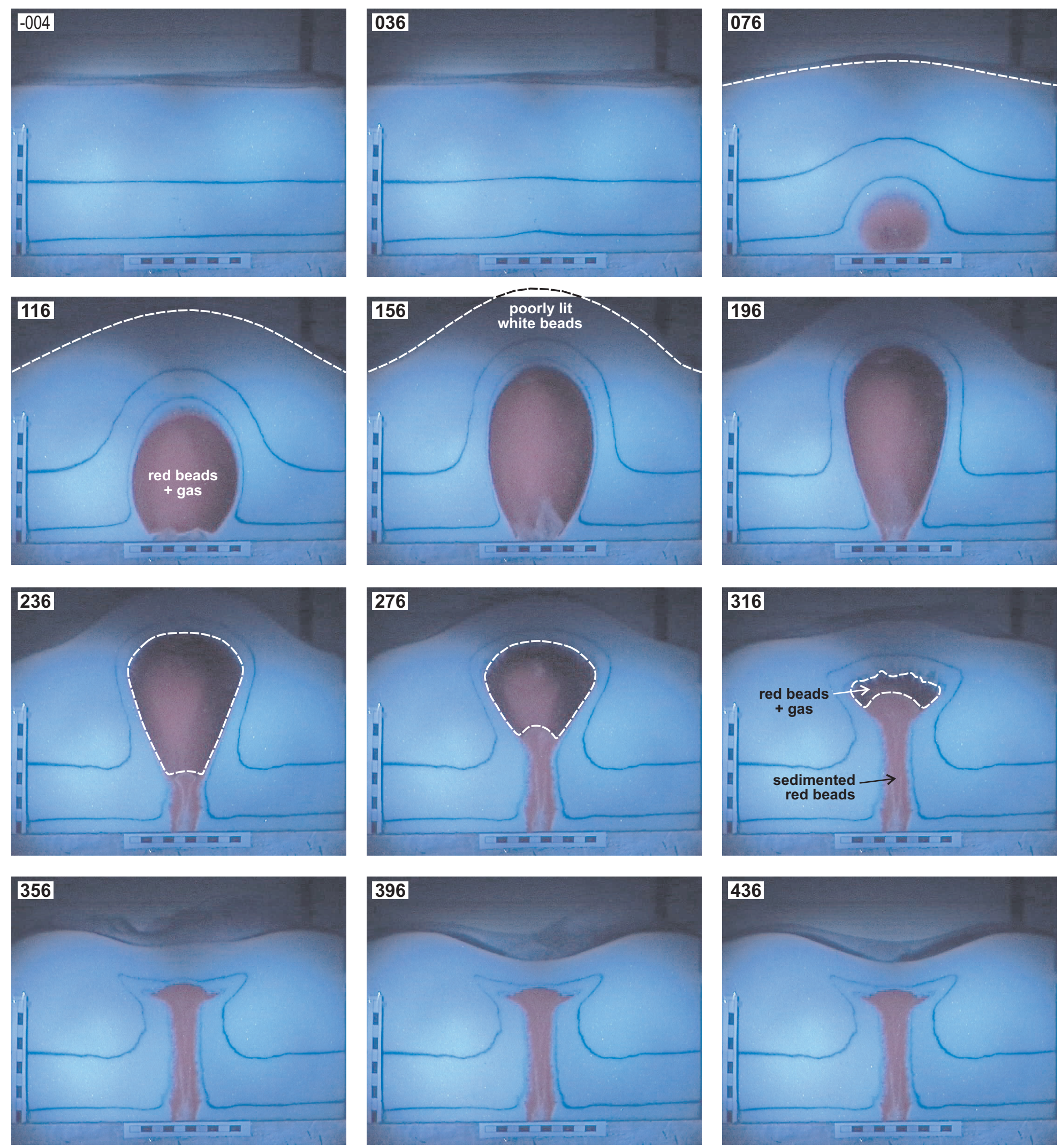

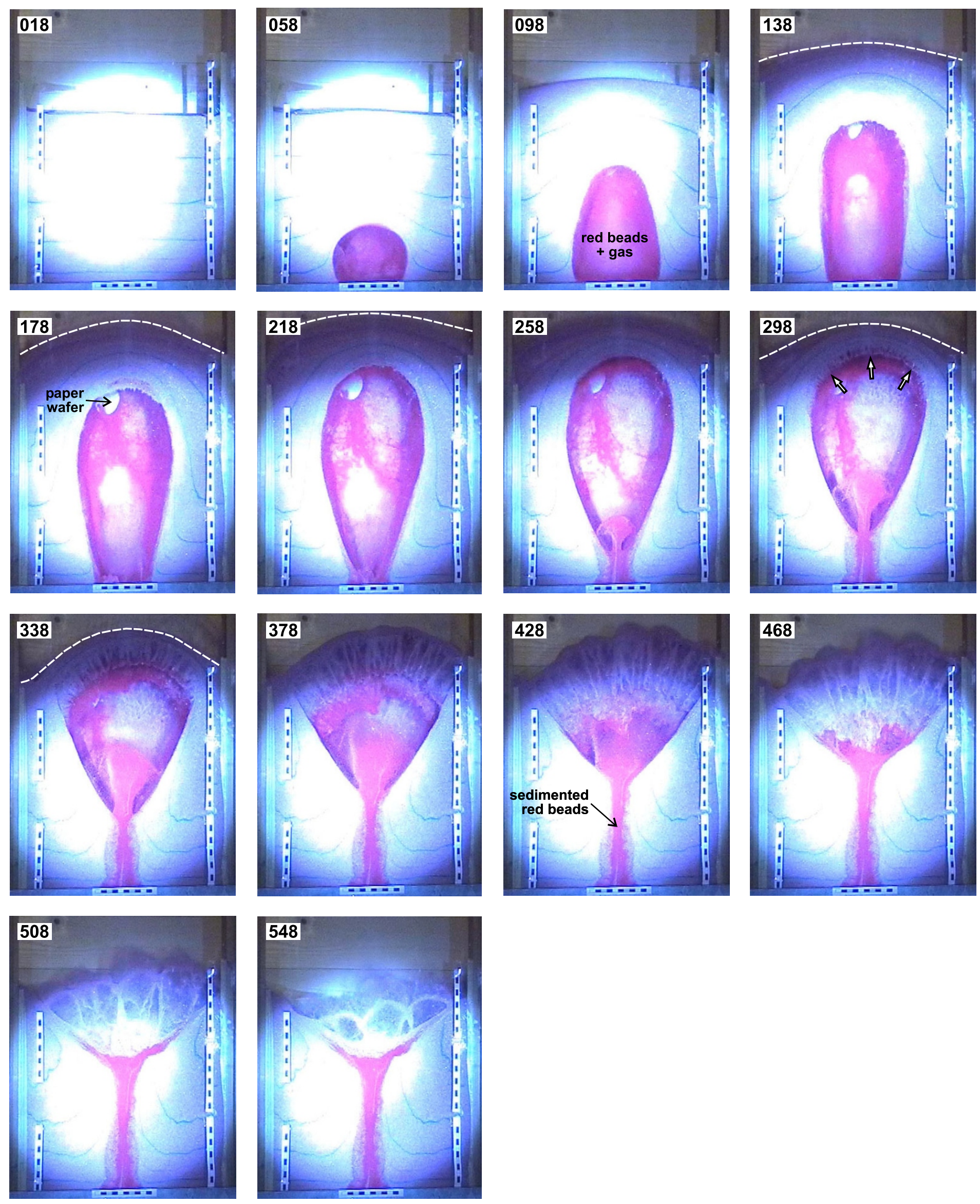

ROSS et al. (JVGR) Fig. 4 

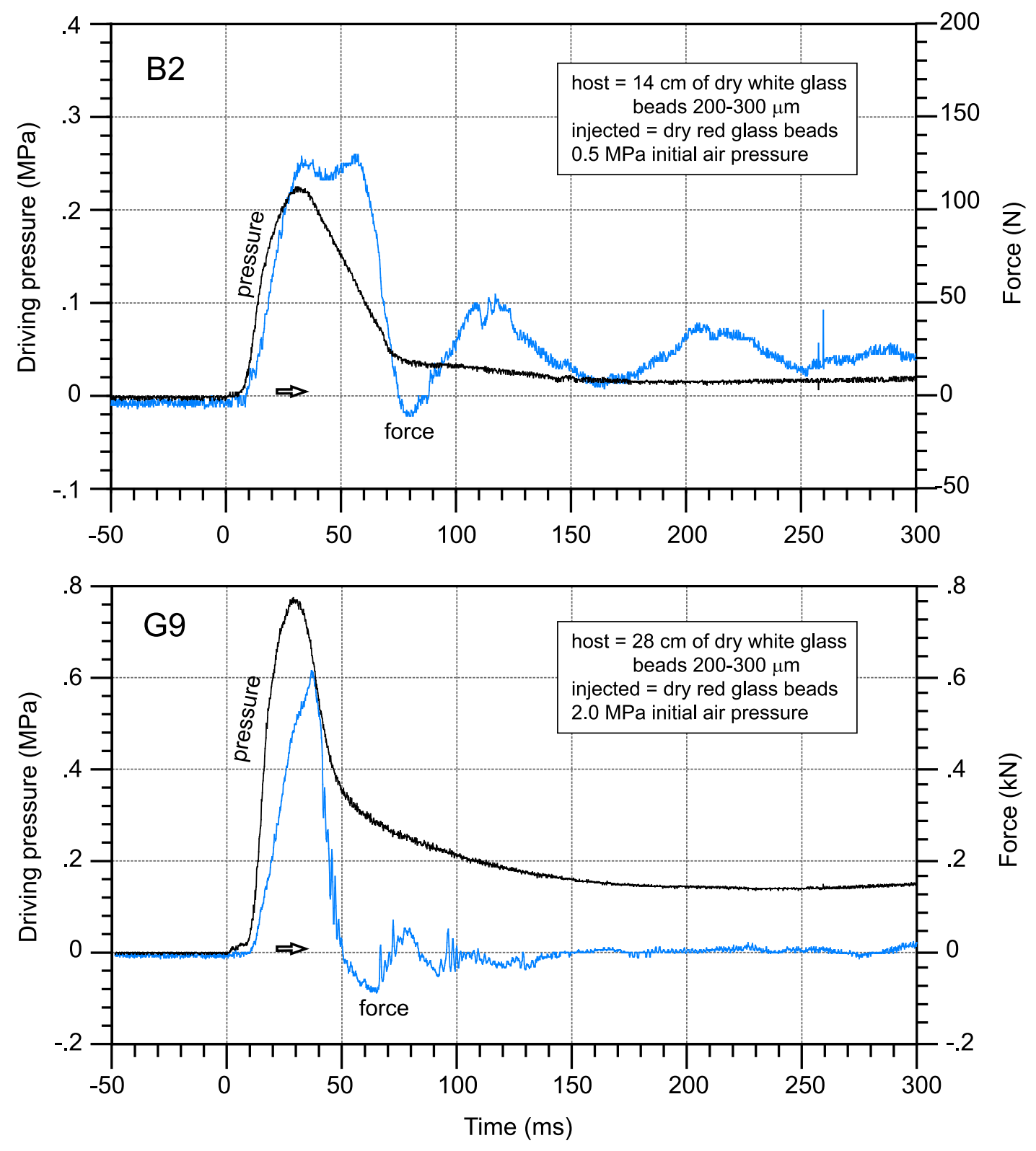

Ross et al (JVGR) Fig. 5 

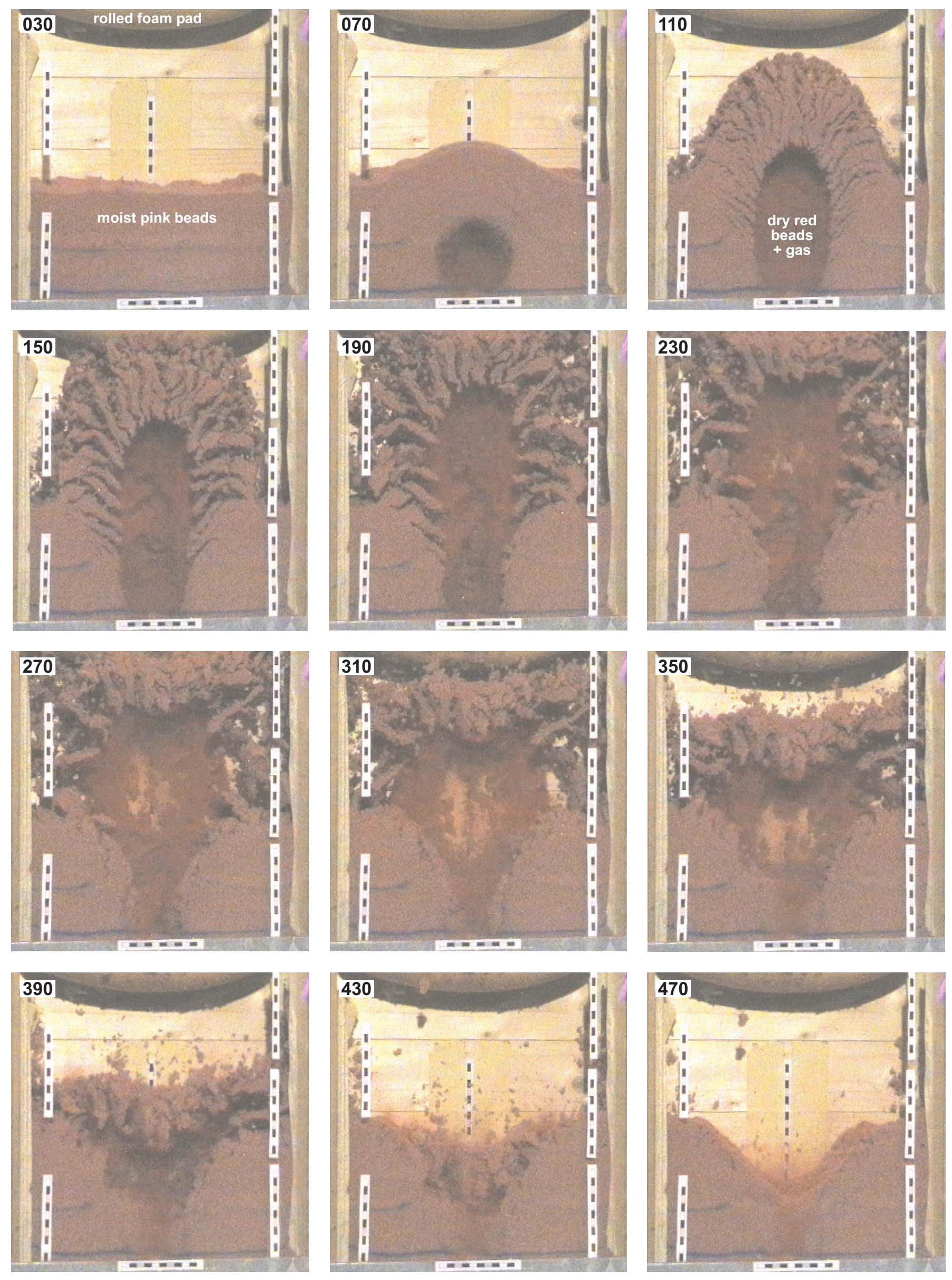